\title{
Prediction of the unsteady ventilated partial cavities
}

\author{
Volodymyr Semenenko ${ }^{1} \bullet$ Olena Naumova ${ }^{1}$
}

Received: 16 September 2020 / Accepted: 21 October 2020

\begin{abstract}
Approximate methods of computing the unsteady ventilated partial cavities created on both the plane and the cylindrical streamlined surfaces have been developed. The cases of plane partial cavities past a slender wedge-shaped cavitator, and axisymmetric partial cavities past a ring flange on the surface of an infinite circular cylinder are considered. Results of computer simulation of the unsteady ventilated partial cavities of both that types are shown. A comparison of the unsteady behavior of plane and axisymmetric ventilated partial cavities is given. A comparative analysis of two methods of controlling the partial cavities by varying the cavitator shape and by regulating the gas supply rate into a cavity is given. It has been shown that the first method is more effective for a partial cavity on a plane. For an axisymmetric partial cavity on a cylinder, both the control methods appear ineffective.
\end{abstract}

Keywords: partial cavity; ventilated cavity; unsteady cavity; discrete singularity method; computer simulation.

\section{Introduction}

One of the ways to reduce the viscous drag of surface ship and underwater vehicle motion is to create elongated cavities on the streamlined surfaces [1]. These cavities are filled with the water vapor or gas. Various types of cavitators may be used to create partial cavities (see Fig. 1). If the flow velocity $V$ is relatively low, then the partial cavities must be ventilated with the volumetric gas supply rate $\dot{Q}_{\text {in }}$.

A large number of experimental and theoretical works are devoted to the study of various problems arising when applying this method. Until now, however, the problems of the unsteady behavior of partial cavities, and also problems of controlling the partial cavities are weak investigated. As examples, we can give problems of the partial cavity reaction to varying the flow velocity $V(t)$, the immersion depth $H(t)$, the air supply rate $\dot{Q}_{\text {in }}(t)$, etc.

O. Naumova

lena.naumova17@gmail.com

${ }^{1}$ Institute of Hydromechanics of the National Academy of Sciences of Ukraine, Kyiv, Ukraine
Control of the partial cavities is specified variations of the cavity dimensions by varying the cavitator shape and/or the gas supply rate, as well as suppression of possible instability of ventilated cavities [2].

The aim of this work is to develop approximate methods for calculating and computer simulation of unsteady ventilated partial cavities on plane and cylindrical surfaces under various unsteady perturbations, and with various methods of the cavity control.

Two practically important types of partial cavities are considered. The first type is the partial cavity past an elongated rectilinear cavitator located on the plane perpendicular to the mainstream (see Fig. 1, a). The second type is the partial cavity past a ring cavitator located on the surface of an infinite circular cylinder, when the mainstream is directed along the cylinder generatrix (see Fig. 1, b). In the first case, the problem can be approximately considered as plane. The method for calculating the plane partial cavities is based on the methods of the linear theory of cavitation flow and the numerical method of discrete singularities $[3,4]$. In the second case, the problem can be approximately considered as axisymmetric. To calculate axisymmetric partial cavities on a cylinder, an approximation method based on the principle of independence of cavity section expansion by G.V.Logvinovich [5-7] was used. Using both the methods, we have developed the rapid computational algorithms that allow us to observe the behavior of unsteady cavities on a computer screen directly during calculation, i.e. to realize computer simulation. 

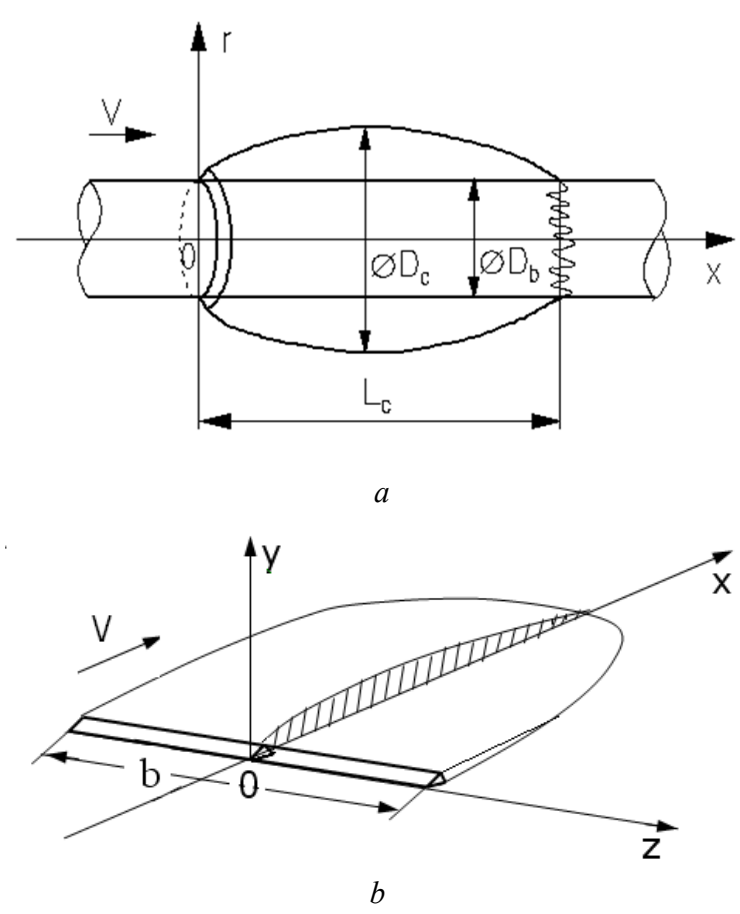

Fig. 1. Sketches of partial cavities: $(a)$ on a plane surface; $(b)$ on a cylinder surface

\section{Solution of plane problem}

If the cavitator, which is located on the flat wall $O x z$ , has sufficiently large aspect ratio $\lambda=b / a>1$ (where $a, b$ are respectively the cavitator chord and the cavitator span), then in the middle sections parallel to the plane $O x y$ , the problem can be approximately considered as plane. Here, we will neglect the boundary layer influence, the gravity and the surface tension influence, as well as the influence of the gas flow inside the partial ventilated cavity on the cavity shape and dimensions.

One considers a plane unsteady problem of cavitation flow of ideal, incompressible, and imponderable fluid around a slender wedge located on a flat wall $y=0$, so that the flow occurs in the upper half-plane $y>0$ (see Fig. 2,a). Its solution coincides with the solution of the problem for infinite fluid and has the form of a set of three functional equations for three unknown functions $q(x, t), l(t)$, $p_{\mathrm{c}}(t)[4]$ :

$$
\begin{gathered}
\int_{0}^{l(t)} \frac{q(s, t) d s}{x-s}+\frac{\partial}{\partial t} \int_{0}^{l(t)} q(s, t) \ln |x-s| d s+\pi p_{c}(t)=\pi p_{w}(t), \\
1<x<l(t) . \\
\int_{0}^{l(t)} q(s, t) d s=0 \\
\frac{d}{d t}\left[p_{c}(t) Q(t)\right]=p_{w}(t)\left[\bar{Q}_{\text {in }}(t)-\bar{Q}_{\text {out }}(t)\right] .
\end{gathered}
$$
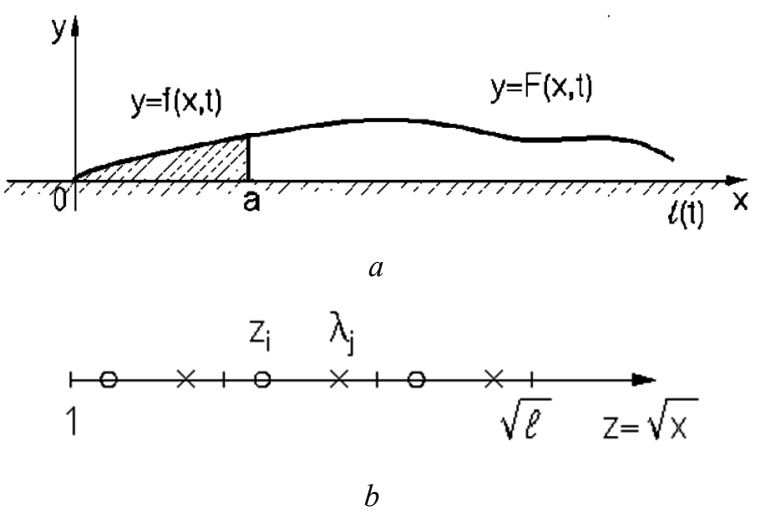

Fig. 2. (a) Plane unsteady partial cavity past a slender wedge; $(b)$ discretization scheme

Here, $q(x, t)$ is the intensity of source distributed on the interval $[0, l(t)] ; p_{\mathrm{c}}(t)$ is the cavity pressure; $p_{w}(t)$ is the specified water pressure; $Q$ is the cavity volume per unit length; $\bar{Q}_{i n}$ and $\bar{Q}_{\text {out }}$ are the coefficients of volumetric gas rates of supply into the cavity and loss from the cavity, respectively, referred to the pressure $p_{w}(0)$. Here and below, all variables are made dimensionless with respect to $a, V$. The source intensity $q_{w}(x, t)$ on the interval $[0,1]$ is determined by the specified cavitator shape:

$$
q_{w}(x, t)=2\left[\frac{\partial f(x, t)}{\partial t}+\frac{\partial f(x, t)}{\partial x}\right] .
$$

The equation of the gas mass in the cavity balance (3) was derived under the assumption that the gas expansion in an unsteady cavity occurs according to the isothermal law. In this case the cavity pressure $p_{c}(t)$ is synchronously varied along the cavity.

The gas supply rate $\dot{Q}_{\text {in }}$ is the specified fixed value or the specified time function when controlling the cavity. In the steady case $\bar{Q}_{\text {in }}=\bar{Q}_{\text {out }}$, the known experimental data give a linear dependence of $\bar{Q}_{\text {out }}$ on $\sigma$ in some interval of the cavitation number variation. So, in work [8], in the case of the vertical plate cavitator one obtained the empirical dependence:

$$
\bar{Q}_{i n}=-0.5293 \sigma+0.2426 \text { when } \sigma=0.1-0.3 .
$$

Here, we will approximate the rate of the gas loss from the unsteady partial cavity with the semi-empirical dependence:

$$
\dot{Q}_{\text {out }}(t)=\gamma B_{c} V\left(1-\frac{\sigma(t)}{\sigma_{v}}\right),
$$

where $\gamma$ is the empirical coefficient; $B_{c}$ is the cavity midsection width; $\sigma_{\mathrm{v}}=2\left(p_{\mathrm{w}}-p_{v}\right) / \rho V^{2}$ is the vapor cavitation number; $p_{v}=2350 \mathrm{~Pa}$ is the saturated vapor pressure; $\sigma=2\left(p_{w}-p_{c}\right) / \rho V^{2}$ is the real cavitation number for the 
same values of $p_{w}, \mathrm{~V}$. Formula (6) gives correct asymptotic $\dot{Q}_{\text {out }} \rightarrow 0$ when $\sigma \rightarrow \sigma_{v}$. A comparison of relation (6) with (5), and also with [9] gives the magnitudes $\gamma=0.02$ -0.04 .

Formulae for determination of both the shape and the volume per unit length of the unsteady cavity are as following:

$$
\begin{gathered}
F(x, t)=\frac{1}{2} \int_{0}^{x} q(s, t-x+s) d s, \quad 1 \leq x \leq l(t) . \\
Q(t)=\int_{1}^{1(t)} F(s, t) d s .
\end{gathered}
$$

\section{Calculation algorithm}

The set of equations (1) - (3) is nonlinear, since $l(t)$ is the unknown time function. We will find its numerical solution at successive times

$$
t^{(n)}=t^{(n-1)}+\Delta t, n=2,3, \ldots
$$

for the starting conditions:

$$
t^{(1)}=0, \quad q^{(1)}(x)=q_{0}(x), \quad l^{(1)}=l_{0}, \quad \sigma^{(1)}=\sigma_{0} .
$$

One replaces the time derivative in equations (1) and (3) with a finite difference of the first order. Then, on the n-th time layer, equations (1) - (3) can be written as following:

$$
\begin{gathered}
\int_{1}^{l^{(n)}} \frac{q^{(n)}(s) d s}{x-s}+\frac{1}{\Delta t} \int_{1}^{l^{(n)}} q^{(n)}(s) \ln |x-s| d s+\pi p_{c}^{(n)}= \\
=\pi p_{w}^{(n)}-A_{1}^{(n)}(x)+\frac{1}{\Delta t} A_{2}^{(n-1)}(x), \quad 1<x<l^{(n)}, \\
\int_{1}^{l^{(n)}} q^{(n)}(s) d s=A_{3}^{(n)}=-\int_{0}^{1} q_{w}^{(n)}(s) d s, \\
p_{c}^{(n)} Q^{(n)}=\mathrm{p}_{c}^{(n-1)} Q^{(n-1)}+\Delta t p_{w}^{(n)}\left(\bar{Q}_{i n}^{(n)}-\bar{Q}_{\text {out }}^{(n)}\right),
\end{gathered}
$$

where functions $A_{1}^{(n)}(x), A_{3}^{(n)}$ in the right part are known, and function $A_{2}^{(n-1)}(x)$ is calculated by data of the previous time layer:

$$
\begin{gathered}
A_{2}^{(n-1)}(x)=\int_{0}^{1} q_{w}^{(n-1)}(s) \ln (x-s) d s+ \\
+\int_{1}^{l^{(n-1)}} q^{(n-1)}(s) \ln |x-s| d s .
\end{gathered}
$$

If the value $l^{(n)}$ at the $n$-th time step is considered to be known, then the set of equations (9), (10) becomes linear and may be effectively solved numerically by the discrete singularity method [3]. To improve the convergence of the method, we change of variables $x \rightarrow z^{2}, s \rightarrow \lambda^{2}$ preliminarily in the integrals of the equations. After that, the cavity projection $\left[1, \sqrt{l^{(n)}}\right.$ ] is partitioned into $M$ equal intervals. Each interval contains a point source and a control point in which equation (9) is satisfied (see Fig. 2, b). The order of location of the singularities $s_{j}$ and control points $x_{i}$ is defined by the function class in which solution of the singular integral equation (9) is sought. It is limited in the point $x=1$ and unlimited in the point $x=l^{(n)}$ :

$$
\begin{gathered}
z_{i}=1+\Delta z(i-0.75), \quad \lambda_{j}=1+\Delta z(j-0.25), \\
\Delta z=\frac{\sqrt{l^{(n)}}-1}{M}, \quad i, j=1,2, \ldots, M .
\end{gathered}
$$

As a result of discretization of equations (9), (10), we obtain the set of $M+1$ linear algebraic equations with respect to the unknowns $q_{j}^{(n)}, p_{c}^{(n)}, j=1,2, \ldots M$ :

$$
\begin{gathered}
\sum_{j=1}^{M} q_{j}^{(n)}\left(\frac{\Delta t}{z_{i}^{2}-\lambda_{j}^{2}}+\ln \left|z_{i}^{2}-\lambda_{j}^{2}\right|\right) \lambda_{j}+\frac{\pi \Delta t}{2 \Delta z} p_{c}^{(n)}= \\
=\frac{\pi \Delta t}{2 \Delta z} p_{w}^{(n)}-\Delta t A_{1}^{(n)}\left(z_{i}\right)+A_{2}^{(n-1)}\left(z_{i}\right) \\
\sum_{j=1}^{M} q_{j}^{(n)} \lambda_{j}=\frac{1}{2 \Delta z} A_{3}^{(n)}=-\sum_{j=1}^{M_{w}} q_{w j}^{(n)} \lambda_{j},
\end{gathered}
$$

where $M_{w}=\frac{1}{\Delta z}$,

$$
\begin{gathered}
A_{1}^{(n)}\left(z_{i}\right)=\sum_{\mathrm{j}=1}^{\mathrm{M}_{\mathrm{w}}} q_{w j}^{(n)}\left[\frac{1}{z_{i}^{2}-\lambda_{j}^{2}}+\frac{1}{\Delta t} \ln \left(z_{i}^{2}-\lambda_{j}^{2}\right)\right] \lambda_{j}, \\
A_{2}^{(n-1)}\left(z_{i}\right)=\sum_{\mathrm{j}=1}^{\mathrm{M}_{\mathrm{w}}} q_{w j}^{(n-1)} \ln \left(z_{i}^{2}-\lambda_{j}^{2}\right) \lambda_{j}+\sum_{\mathrm{j}=1}^{\mathrm{M}} q_{j}^{(n-1)} \ln \left|z_{i}^{2}-\lambda_{j}^{2}\right| \lambda_{j} .
\end{gathered}
$$

After discretization, formulae (7), (8) have the form:

$$
\begin{gathered}
F_{i}^{(n)}=f^{(n)}(1)+\frac{\Delta x_{0}}{2} \sum_{j=1}^{i} q_{j}^{(n-i+j)}=F_{i-1}^{(n-1)}+\frac{\Delta x_{0}}{2} q_{i}^{(n)}, \\
i=2,3, \ldots, M^{(n)} . \\
Q^{(n)}=\Delta x_{0} \sum_{i=1}^{M^{(n)}} F_{i}^{(n)}
\end{gathered}
$$

where $\Delta x_{0}=\frac{l_{0}-1}{M}, i=2,3, \ldots, M^{(n)}$.

It is assumed that the values of the function $q_{i}^{(n)}$ are known in the nodes of a fixed rectangular grid with the step $\Delta t$ in direction to $n$ and with the step $\Delta x_{0}$ in direction to $i$. Since these nodes do not coincide with the nodes of the computational grid, the values $q_{i}^{(n)}$ are preliminarily obtained by interpolation. 
We consider the cavity length $l(t)$ as a free parameter and determine it at successive times $t^{(n)}$ by numerically solving functional equation (11) by the iterative method. At each iteration, the solution is calculated for fixed $l^{(n)}=l\left(t^{(n)}\right)$ from the set of linear algebraic equations (13), (14).

Note that the condition of equality to zero of the total intensity of the sources (2) ensures the limitation of the pressure at infinity, but the unsteady cavity is open-ended. In this case, during computation the cavity thickness in the point $x=l^{(n)}$ can become both positive and negative. We will assume that only that part of the cavity with $F(x, t) \geq$ 0 has the physical meaning. For each $t^{(n)}$ this condition is fulfilled on some interval $\left[1, l_{r}^{(n)}\right]$, where $l_{r}^{(n)} \leq l^{(n)}$. We will consider the value $l_{r}^{(n)}$ as the real cavity length and use it instead of $l^{(n)}$ when calculating the cavity volume $Q^{(n)}$ by formula (16).

\section{Solution of axisymmetric problem}

Let us now consider the problem of an axisymmetric cavity past a ring cavitator (flange) on the surface of an infinite circular cylinder in the flow of ideal incompressible fluid (see Fig. 1, $b$ ). The cavitation number $\sigma$ is considered to be small. The flange height $h$ is considered to be small compared to the cylinder diameter $D_{b}$. As above, we will neglect the boundary layer influence, the gravity and the surface tension influence, as well as the influence of the gas flow inside the ventilated partial cavity on the cavity shape and dimensions.

In contrast to plane problems, axisymmetric problems on cavitation flows do not have exact solutions. We construct an approximate solution of the problem using the energetic and asymptotic methods [5-7]. It is known that an axisymmetric cavity has in its middle part the shape of an ellipsoid of revolution with the minor and major axes $D_{c}$ and $L_{c}$. In the case of small cavitation numbers for steady axisymmetric supercavities past blunted cavitators, the following semi-empirical relations are established [5]:

$$
D_{c}=D_{n} \sqrt{\frac{c_{x}}{\kappa \sigma}}, \quad L_{c}=D_{n} \frac{A \sqrt{c_{x}}}{\sigma},
$$

where $D_{c}$ and $L_{c}$ are the supercavity mid-section diameter and length, respectively; $D_{n}$ is the cavitator diameter; $c_{x}$ is the cavitation drag coefficient; $\sigma$ is the cavitation number; $\kappa=0.9-1.0, \quad A \approx 2.0$ are the empiric constants. It follows from here that the cavity aspect ratio $\lambda$ does not depend on the shape and dimension of the cavitator, it depends only on the cavitation number:

$$
\lambda=\frac{L_{c}}{D_{c}}=\frac{A \sqrt{\kappa}}{\sqrt{\sigma}} .
$$

In Chapter 5 of book [10], the relation for the midsection diameter of the cavity past the ring flange on a cylinder was obtained using the momentum theorem:

$$
D_{c}=D_{b} \sqrt{1+\frac{4 c_{x r} \bar{h}(1+\bar{h})}{\kappa \sigma}},
$$

where $\bar{h}=h / D_{b} ; c_{x r}$ is the cavitation drag coefficient for the ring flange:

$$
c_{x r}=\frac{2 F_{x r}}{\rho V^{2} S_{r}}, \text { where } S_{r}=\frac{\pi\left(D_{b}+2 h\right)^{2}}{4}-\frac{\pi D_{b}^{2}}{4} .
$$

The length $L_{e}$ of the major axis of the ellipsoid approximating the cavity shape can be determined by formula (18). If we draw the ellipse contour directly through the cavitator edge, then the distance of the edge from the left end of the ellipse is as following (see Fig. 3):

$$
x_{0}=\frac{L_{e}}{2}\left[1-\sqrt{1-\left(\frac{R_{b}+h}{R_{c}}\right)^{2}}\right] \text {. }
$$

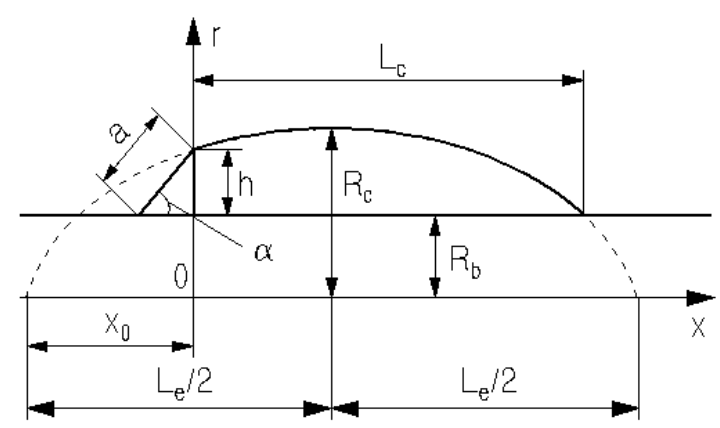

Fig. 3. Design scheme of axisymmetric partial cavity past a ring flange on a cylinder

The shape of a steady ellipsoidal cavity is determined by equation $[6,7]$ :

$$
\frac{\partial^{2} S(x)}{\partial x^{2}}=-\frac{k_{1} \sigma}{2}, \quad 0 \leq x \leq L_{c},
$$

where $S$ is the cavity section area; $k_{1}$ is the semi-empirical constant. Twice integrating this equation and requiring the fulfillment of two obvious relations:

$$
S\left(\frac{L_{\mathrm{e}}}{2}-\mathrm{x}_{0}\right)=\frac{\pi D_{c}^{2}}{4}, \quad \frac{\partial S}{\partial t}\left(\frac{L_{e}}{2}-\mathrm{x}_{0}\right)=0,
$$

we obtain the calculation formula:

$$
S(x)=\frac{\pi D_{1}^{2}}{4}+\frac{k_{1} \sigma}{4}\left(x-x_{1}\right)\left(L_{e}-2 x_{0}-x+x_{1}\right)
$$




$$
k_{1}=\frac{4 \pi\left(\mathrm{D}_{\mathrm{c}}^{2}-D_{n}^{2}\right)}{\sigma\left(L_{\mathrm{e}}-2 x_{0}\right)^{2}}, \quad x_{1} \leq x \leq L_{c}
$$

The real cavity length past the flange $L_{c}<\mathrm{L}_{\mathrm{e}}$ is determined from the condition $\mathrm{S}\left(L_{c}\right)=\pi D_{b}^{2} / 4$.

It is taken into account in expression (24), that equation (22) is not valid for some transition interval $0 \leq x \leq x_{1}$ near the cavitator. On the interval $0 \leq x \leq x_{1}$, the cavity shape is calculated using another formula, usually empirical one [5]. In the point $x=x_{1}$, both the formulae should be matched so that the composite cavity contour does not have a roughness ( $D_{1}$ is the cavity diameter in the agreement point).

In this case, since the flange height is small $\bar{h}<<1$, the flow near the flange weak differs from the plane flow [10]. Therefore, the exact solution of the plane problem can be taken as the cavity shape on the transition section $0 \leq x \leq x_{1}$.
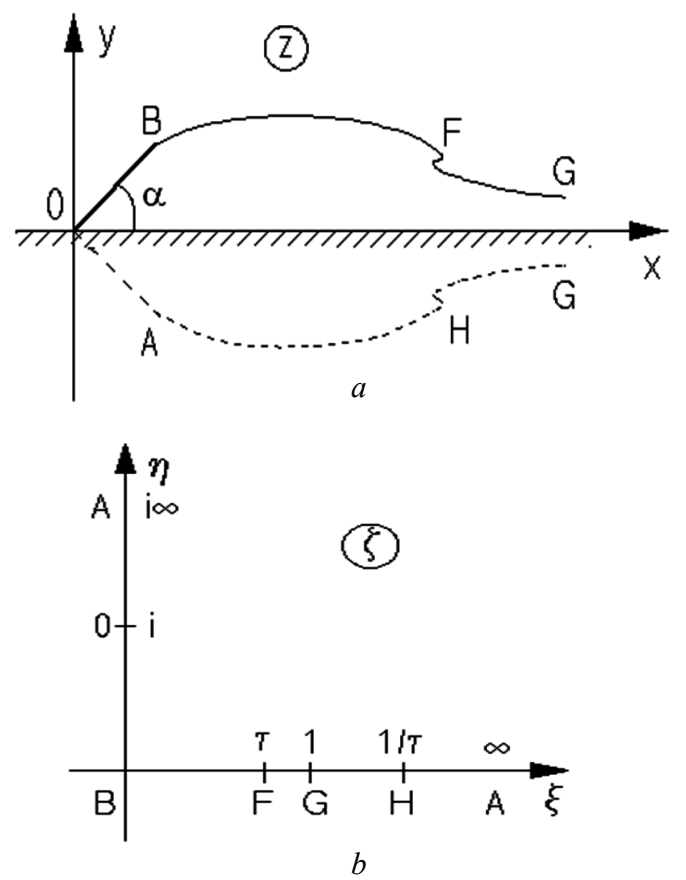

Fig. 4. Scheme of cavitation flow past a wedge: (a) physical plane; (b) parameter plane

Here we use the solution of the plane nonlinear problem of cavitation flow around a wedge located on the flat wall according to M.Tulin's 2nd scheme [11] (see Fig. 4,a). Let us denote: $a$ is the wedge side length, $\alpha=\pi \mu$ is the wedge angle.

This problem is equivalent to the problem of infinite cavitation flow around a symmetric wedge with the angle $2 \alpha$. Its solution is effectively constructed by the Chaplygin singular point method [11] by conformal mapping of the flow region and the complex potential region
$W=\phi+i \psi$ onto the first quadrant of the parametric variable plane $\varsigma=\xi+i \eta$ (see Fig. $4, b$ ):

$$
\begin{gathered}
\frac{d W}{d \varsigma}=\kappa \sqrt{1+\sigma} \frac{\varsigma\left(1+\varsigma^{2}\right)}{\left(1-\varsigma^{2}\right)^{3}}, \\
\frac{d W}{d z}=e^{i \pi \mu} \sqrt{1+\sigma}\left(\frac{\varsigma-i}{\varsigma+i}\right)^{2 \mu}\left[\frac{(\varsigma+\tau)(\varsigma \tau-1)}{(\varsigma-\tau)(\varsigma \tau+1)}\right]^{i \gamma},
\end{gathered}
$$

where $\gamma=\frac{1}{2 \pi} \ln (1+\sigma) ; \quad \tau=-\frac{\gamma}{\mu}+\sqrt{1+\left(\frac{\gamma}{\mu}\right)^{2}} ; \kappa$ is the scale coefficient. Here, all the variables were made dimensionless with respect to $a$ and $V$. Correspondence of points of the parametric and the physical planes is given by the formula:

$$
z(\varsigma)=e^{i \pi \mu}+\kappa e^{-i \pi \mu} \int_{0}^{\varsigma} \Phi(\varsigma) d \varsigma
$$

where $\Phi=\frac{1}{\kappa} e^{i \pi \mu} \frac{d z}{d w} \frac{d w}{d \varsigma}$

From here, the shape of the upper cavity boundary may be calculated by assuming $0<\xi<\tau, \eta=0$. We obtain the value of the scale coefficient by calculating the wedge side length:

$$
\kappa \int_{0}^{1}|\Phi(\eta)|_{\xi=0} d \eta=1
$$

The cavitation drag of the ring flange on a cylinder is equal to:

$$
F_{x r}=\pi \rho V^{2} \int_{0}^{1} \bar{p}(\eta)\left[\bar{R}_{b}+y(\eta)\right] \frac{d y}{d \eta} d \eta
$$

where $\bar{p}(\eta)=1-\left|\frac{d W}{d z}\right|^{2}, \quad \bar{R}_{b}=\frac{D_{b}}{2 a}$.

It was shown in work [10] in the case $\alpha=90^{\circ}$ that the agreement point $x_{1}$ moves away from the cavitator edge with increasing the cylinder diameter $D_{b}$. When calculating, the value $x_{1}$ should be selected in each individual case.

The method of calculating the unsteady axisymmetric cavity shape is based on the principle of independence of the supercavity section expansion by G.V.Logvinovich [5]. The mathematical expression of the independence principle is equation of expansion of the axisymmetric cavity section $[6,7]$ :

$$
\frac{\partial^{2} S(\tau, t)}{\partial t^{2}}=-\frac{k_{1} \sigma(t)}{2}, \quad t-L_{c}(t) \leq \tau \leq t,
$$


where $\tau$ is the instant of formation of the section $x$; $\sigma(t)=2\left[p_{w}(t)-p_{c}(t)\right] / \rho V^{2}$. The perturbed water pressure $p_{w}(t)$ is assumed to be specified, the cavity pressure $p_{c}(t)$ for ventilated cavities is an unknown time function.

According to the independence principle, the constant $k_{1}$ and the starting velocity of the section expansion must be the same for steady and unsteady cavities. From this we obtain the starting conditions for equation (30):

$$
S(\tau, \tau)=\frac{\pi D_{1}^{2}}{4}, \frac{\partial S(\tau, \tau)}{\partial t}=\frac{k_{1} \sigma(\tau)}{4}\left(L_{e}-2 x_{0}\right) .
$$

Twice integrating equation (30) with starting conditions (31), we obtain the calculation formula:

$$
S(\tau, t)=\frac{\pi D_{1}^{2}}{4}+\frac{k_{1}}{4}\left[\sigma(\tau)\left(L_{e}-2 x_{0}\right)(t-\tau)-2 \int_{\tau}^{t}(t-s) \sigma(s) d s\right]
$$

At each time instant, the cavity length is determined from the condition:

$$
\mathrm{S}\left(\mathrm{t}-L_{c}(t), t\right)=\frac{\pi D_{b}^{2}}{4}
$$

In the ventilated cavity case, the equation of the gas mass in the cavity balance during its isothermal expansion (3) is added to relation (32). Dividing all terms of Eq. (3) by $\sigma_{0}$ and integrating it for $t>0$, we obtain the calculation formula:

$$
\bar{p}_{c}(t) Q(t)=\bar{p}_{c}(0) Q(0)+\beta \int_{0}^{t}\left[\bar{Q}_{i n}(s)-\bar{Q}_{\text {out }}(s)\right] d s
$$

where $\bar{p}_{c}=p_{c} / \sigma_{0}=\beta-\bar{\sigma}(t) ; \sigma=\sigma / \sigma_{0} ; \beta=\sigma_{v} / \sigma_{0} \geq 1$ is the similarity parameter for gas-filled cavities; $\sigma_{v}=2\left(p_{\infty}-p_{v}\right) / \rho V_{\infty}^{2}$ is the vapor cavitation number; $p_{v}$ $=2350 \mathrm{~Pa}$ is the saturated vapor pressure; $\bar{Q}_{\text {in }}$ and $\bar{Q}_{\text {out }}$ are the coefficients of volumetric gas flow rates into the cavity and from the cavity, which are referred to the water pressure $p_{w}$ :

$$
\bar{Q}_{\text {in }}=\frac{\dot{Q}_{\text {in }}}{V D_{b}^{2}}, \quad \bar{Q}_{\text {out }}=\frac{\dot{Q}_{\text {out }}}{V D_{b}^{2}} .
$$

Basing on results of a series of experiments [12], we proposed the semi-empirical formula for the volumetric gas loss rate when a ventilated cavity is closed on a cylindrical body:

$$
\dot{Q}_{\text {out }}=\gamma_{b} V D_{c} L_{c}\left(1-\frac{D_{b}^{2}}{D_{c}^{2}}\right)
$$

where $\gamma_{b}$ is the empiric coefficient which weakly depends on $\sigma$. Formula (36) gives the correct asymptotic $\dot{Q}_{\text {out }} \rightarrow 0$ when $D_{b} \rightarrow D_{c}$. When $D_{b} \rightarrow 0$, it gives the gas loss rate for the case of free closure of the cavity with weak gravity influence [13].

In the unsteady case, it is more convenient to use the law (6) describing the dependence of gas loss from the cavity on the variable cavity pressure:

$$
\dot{Q}_{\text {out }}(t)=\gamma_{b 1} V D_{c} L_{c}\left(1-\frac{\sigma(t)}{\sigma_{v}}\right) .
$$

In the case of a natural (vapor) supercavity, we have $\beta=1, \bar{Q}_{\text {in }}=\bar{Q}_{\text {out }}=0$, and equation (3) degenerates into the condition of cavity pressure constancy $\sigma=\sigma_{v}$. At each time instant, the partial cavity volume is equal to:

$$
Q(t)=\int_{0}^{\mathrm{L}_{\mathrm{c}}(t)}\left[S(s, t)-S_{b}\right] d s .
$$

During calculation, the cavity part may be separated, and a jump of functions $L_{c}(t), Q(t)$ may occur (see Fig. 5). In this case at the separation instant $t=t_{1}$ functions $L_{c}(t)$ and $Q(t)$ are stepwisely decreased from $L_{c 1}=L_{c}\left(t_{1}-\Delta t\right), Q\left(t_{1}-\Delta t\right)$ to $L_{c 2}=L_{c}\left(t_{1}\right), Q\left(t_{1}\right)$, but the cavity pressure are not changed: $p_{c}\left(t_{1}-\Delta t\right)=p_{c}\left(t_{1}\right)$. When $t>t_{1}$, equation (34) is replaced by the equation:

$$
\bar{p}_{c}(t) Q(t)=\bar{p}_{c}\left(t_{1}\right) Q\left(t_{1}\right)+\beta \int_{t_{1}}^{t}\left[\bar{Q}_{\text {in }}(s)-\bar{Q}_{\text {out }}(s)\right] d s .
$$

The similar transformation of equation (34) occurs at each separation of the cavity part.

The same algorithm is used to calculate the discontinuous oscillation of the plane partial cavities (see above Section 3).

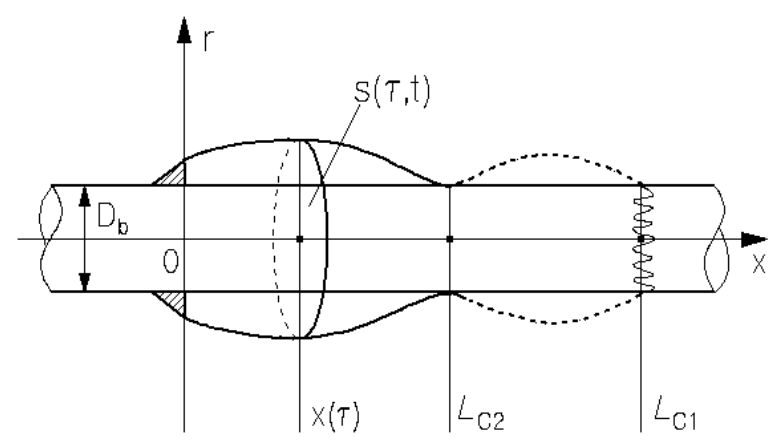

Fig. 5. Scheme of separation of the unsteady cavity part

\section{Calculation results: plane cavities}

Examples of calculating the unsteady partial cavities for specified variation of the wedge angle $y=\alpha(t) x$ and 
the gas supply rate $\dot{Q}_{i n}(t)$ are given below. All the calculations were performed for fixed parameters $a=100.0 \mathrm{~mm}$, $\alpha_{0}=7.5^{\circ}, \gamma=0.04$.

Fig. 6 shows the graphs of variation of the relative length of the partial vapor cavity $\bar{L}_{c}=(l-1) /\left(l_{0}-1\right)$ and the dimensionless volume per unit length $\bar{Q}=Q / a^{2}$ under stepwise $(a)$ and periodic $(b)$ variation of the wedge angle.

As one can see, the cavity reaction is delayed and asymmetric. Under periodic perturbations, this develops in phase shift of the cavity oscillation.
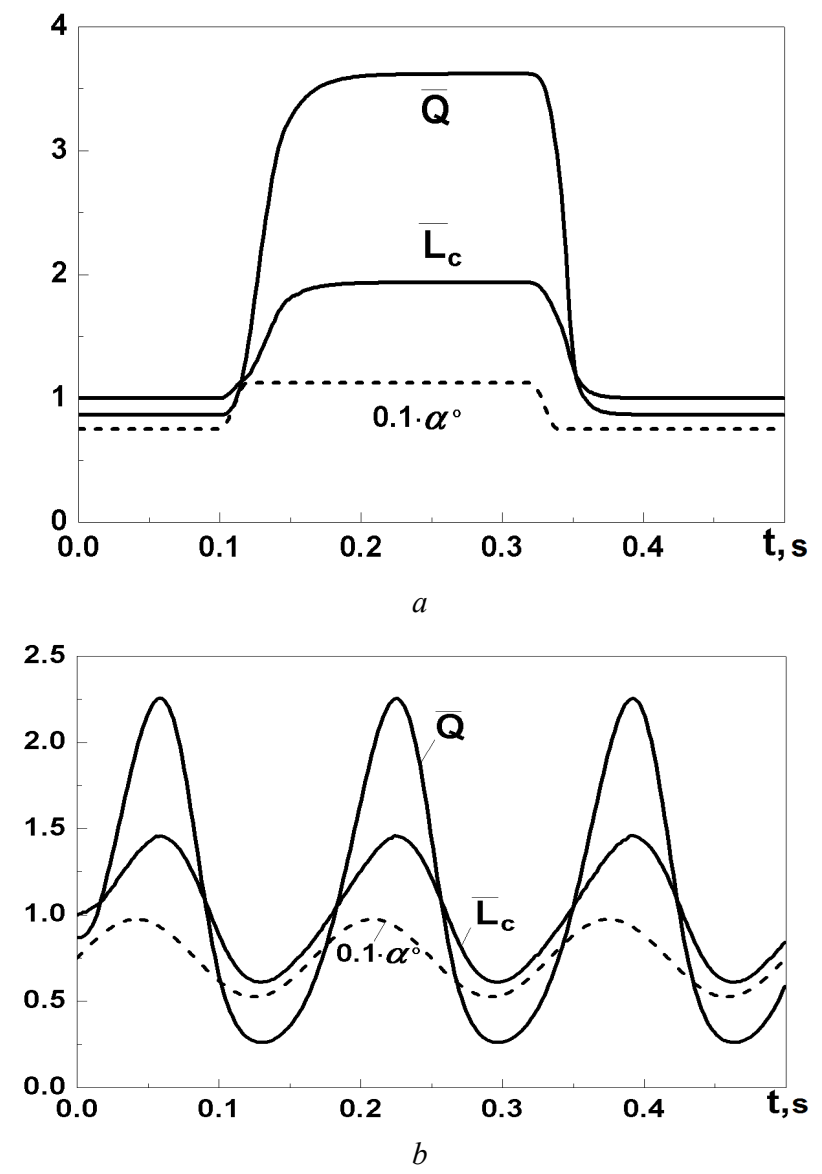

Fig. 6. Variation of $L_{c}$ and $Q$ under variation of $\alpha:(a)$ stepwise, $(b)$ periodic

Fig. 7 shows the graphs of variation of the relative length of the ventilated cavity $\bar{L}_{c}(a)$ and dimensionless cavity pressure $p_{c}{ }^{\prime}=p_{c} / \rho V^{2}(b)$ for a number of values of the excess gas supply coefficient $\bar{Q}_{\text {ext }}(t)$. The calculations were performed for the following initial values of parameters: $V=30.0 \mathrm{~m} / \mathrm{s}, L_{c 0}=500.0 \mathrm{~mm}$. The calculated initial parameters of the ventilated cavity are: $p_{\mathrm{c}}=41.740$ $\mathrm{KPa}, \bar{Q}_{\text {out }}=0.0235, \sigma_{0}=0.1469$. It is assumed that the fixed balanced gas supply $\bar{Q}_{i n}=\bar{Q}_{\text {out }}$ acts when $t<0$. At the time instant $\mathrm{t}=0$, the gas supply $\bar{Q}_{\text {in }}=\bar{Q}_{\text {out }}(0)+\bar{Q}_{\text {ext }}$ starts.
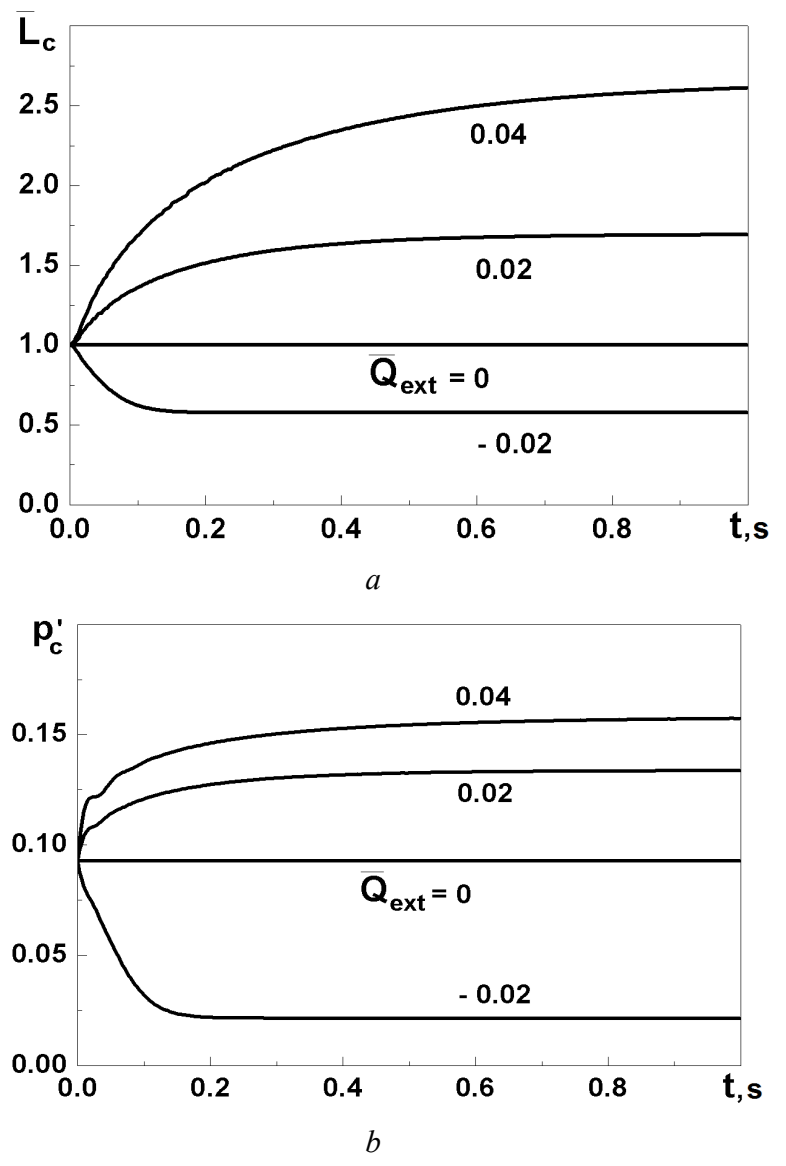

Fig. 7. Variation of $L_{c}(a)$ and $p_{\mathrm{c}}(b)$ at fixed $\dot{Q}_{i n}$

As one can see, in both the cases of excessive and insufficient gas supply, the cavity length and cavity pressure are varied until a new balanced value of the gas loss coefficient $\bar{Q}_{\text {out }}=\bar{Q}_{\text {in }}$ is set. The time for settling the balanced regime increases with increasing the gas supply intensity.

Fig. 8 shows the graphs of varying $\bar{L}_{c}$ and $p_{c}^{\prime}$ under stepwise $(a)$ and periodic $(b)$ variation of the gas supply rate. A comparison with Fig. 6 shows that the cavity reacts much slower to the gas supply variation than to the cavitator shape variation.

Fig. 9 shows the graphs of variation of $\bar{L}_{c}(a)$ and $p_{c}^{\prime}(b)$ at abrupt turning-off the gas supply $\left(\bar{Q}_{i n}=\bar{Q}_{o u t}\right.$ when $t \leq 0, \bar{Q}_{i n}=0$ when $t>0$ ) for a number of immersion depths $H$. The calculations were performed for the flow velocity $V=30.0 \mathrm{~m} / \mathrm{s}$, the starting cavity length $L_{c 0}=500.0 \mathrm{~mm}$ and fixed $\sigma_{0}=0.1469$.

As one can see, when the gas supply is turned off, the pressure and length of the cavity are rapidly decreased until the value $p_{c}=p_{v}$ is attained. In this case, the higher $H$, the higher the cavity collapsing speed. 

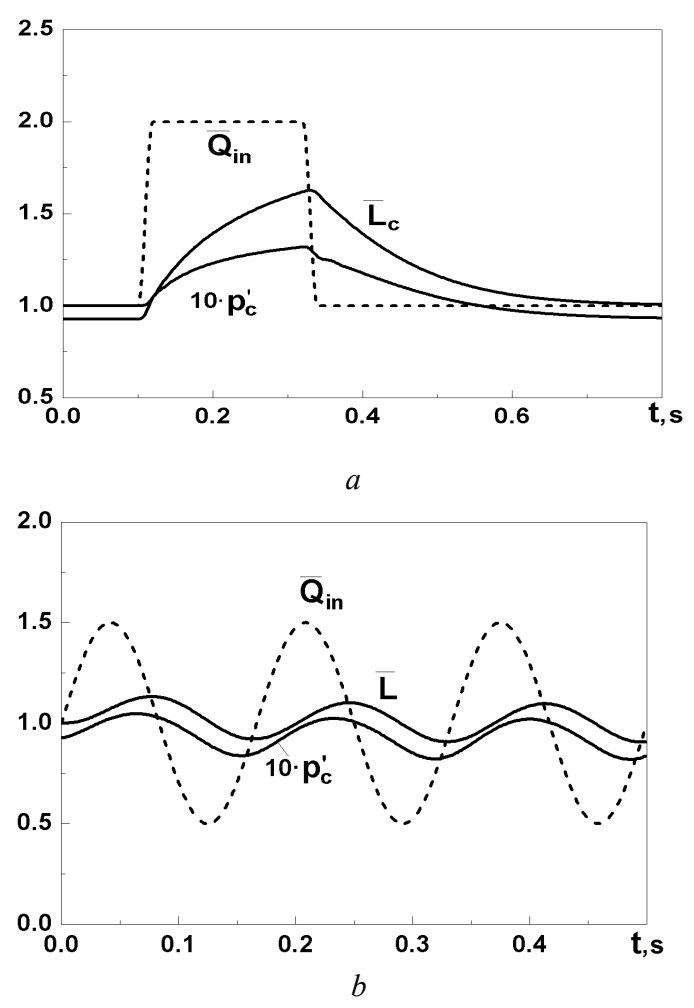

Fig. 8. Variation of $L_{c}$ and $p_{c}$ under variation of $\dot{Q}_{\text {in }}:(a)$ stepwise, $(b)$ periodic

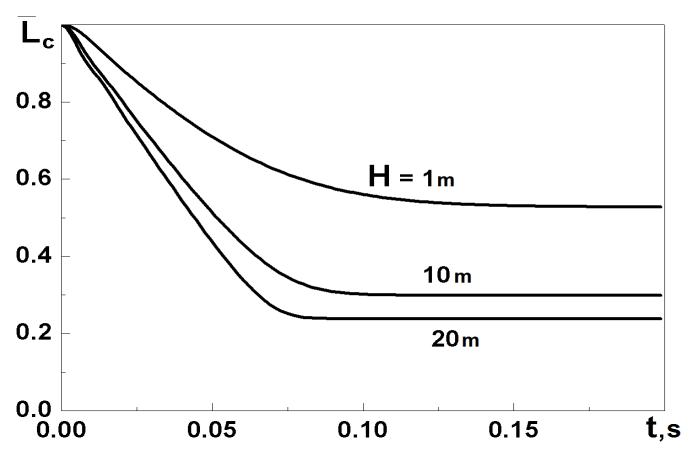

$a$

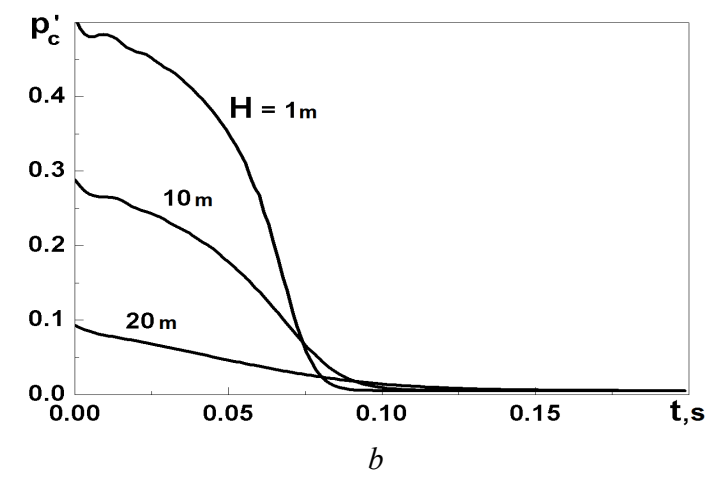

Fig. 9. Effect of immersion depth $H$ on variation of $L_{c}(a)$ and $p_{c}(b)$ after the gas-supply turning off
The developed calculation method makes it possible to solve a number of practical problems of the partial cavity control. As an example, Fig. 10 shows the processes of compensation of the plane partial cavity length decrease caused by decrease of the flow velocity $V(t)$ by regulating the wedge angle $\alpha(t)(a)$ and by regulating the gas supply rate $\dot{Q}_{\text {in }}(t)(b)$.
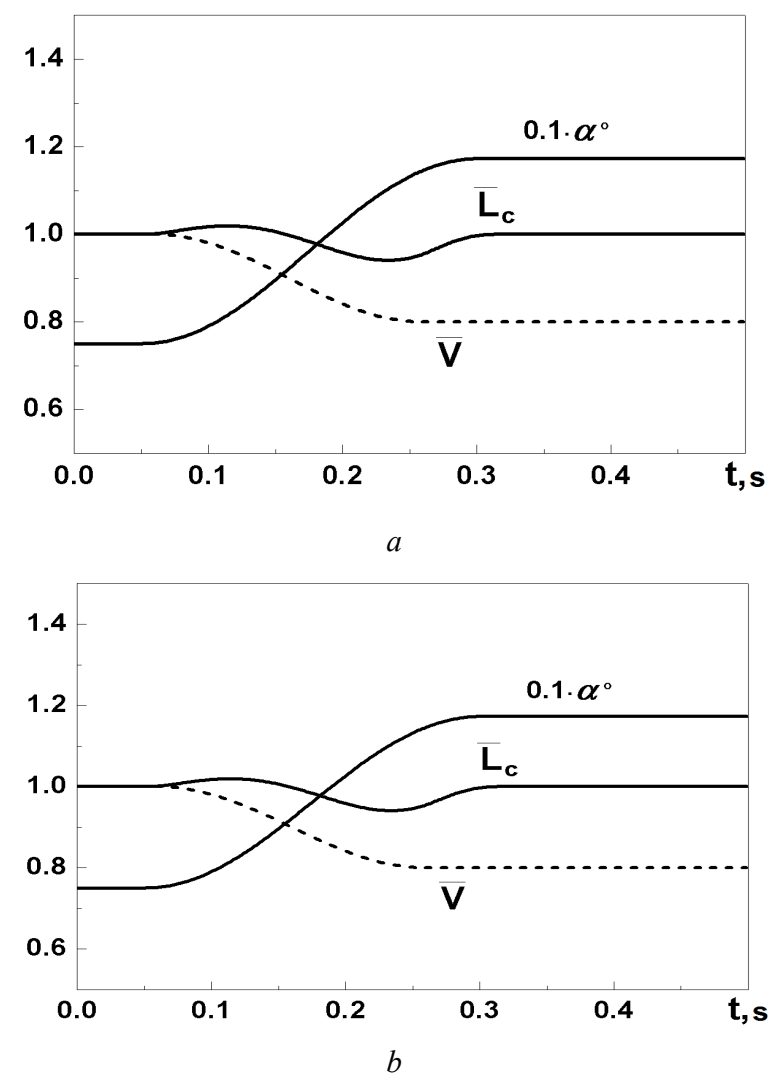

Fig. 10. Compensation of the plane partial cavity length decrease: $(a)$ by regulating $\alpha,(b)$ by regulating $\dot{Q}_{\text {in }}$

As one can see, compensation of the plane partial cavity length decrease by regulating $\dot{Q}_{i n}$ requires longer time due to the slower cavity reaction to the control action. This makes control of the plane partial cavity by regulating $\dot{Q}_{i n}$ less effective than control by regulating $\alpha$.

\section{Calculation results: axisymmetric cavities}

In contrast to a freely closing supercavity past a disc or past a cone, the relative length of the partial cavity on a cylin$\operatorname{der} \bar{L}_{c}=L_{c} / h$ depends not only on $\alpha$ and $\sigma$, but also on $D_{b}$. Fig. 11 shows the graphs of dependencies $c_{x r}$ and $\bar{L}_{c}$ on $\bar{D}_{b}=D_{b} / h$ for $\sigma=0.1$ for a number of $\alpha$. 

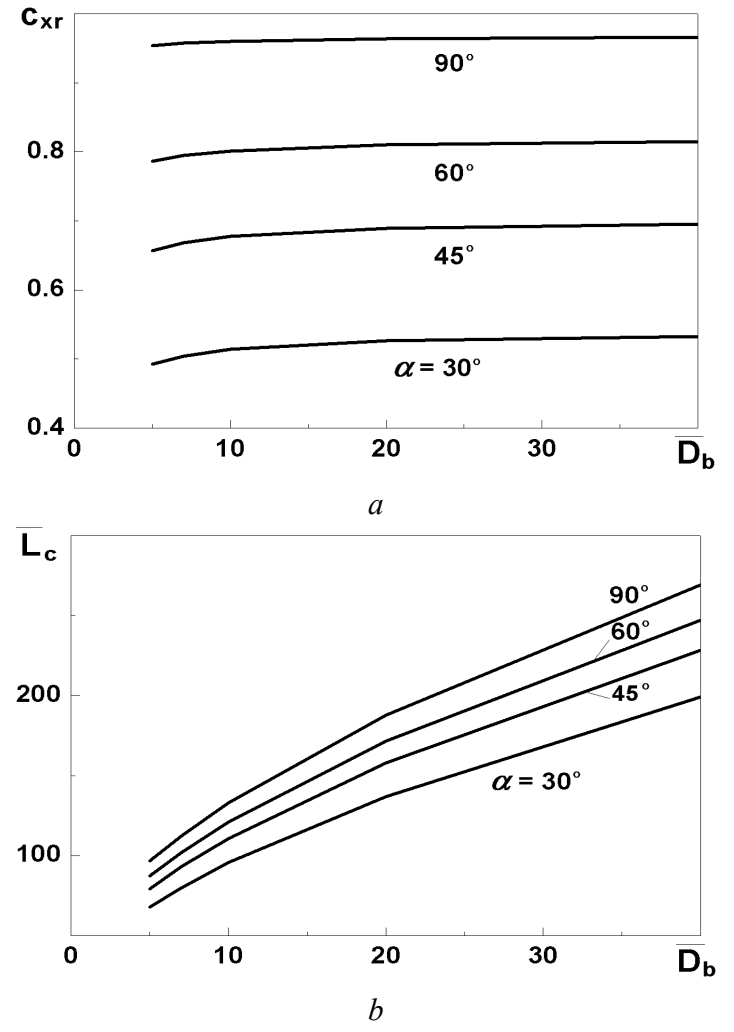

Fig. 11. Effect of the cylinder diameter on $c_{x r}$ (a) and on $L_{c}(b)$

Examples of the calculation of unsteady axisymmetric partial cavities past the ring flange on a cylinder for specified variation of both the cavitator wedge angle $\alpha(t)$ and the gas supply rate $\dot{Q}_{i n}(\mathrm{t})$ are given below. All the calculations were performed for fixed parameters $D_{b}=200.0 \mathrm{~mm}, a=10.0 \mathrm{~mm}, \sigma_{0}=0.1, x_{1}=40.0 \mathrm{~mm}$, $\gamma_{b 1}=0.006$.

Fig. 12 shows the graphs of variation of the dimensionless length $L_{c}{ }^{\prime}=L_{c} / D_{b}$ and dimensionless volume $Q^{\prime}=Q / D_{b}^{3}$ of the vapor partial cavity on a cylinder under stepwise $(a)$ and periodic $(b)$ variation of the angle $\alpha$ (compare with Fig. 6).

Fig. 13 shows the graphs of variation of $L_{c}{ }^{\prime}(a)$ and dimensionless cavity pressure $p_{c}{ }^{\prime}=p_{\mathrm{c}} / \rho V^{2} \quad(b)$ for $\alpha_{0}=45.0^{\circ}$ under stepwise $(a)$ and periodic $(b)$ variations of the gas supply rate $\dot{Q}_{i n}$ (compare with Fig. 8).

As one can see, the partial cavity past the flange on a cylinder reacts very weakly to variation of both the wedge-shaped cavitator angle and the gas supply rate when $h<<D_{b}$. This is explained by the fact that in this case the cavity dimensions are defined mainly by the parameter $D_{b}$ , which value is fixed (see (19)). Thus, both methods of controlling the partial cavity are ineffective in this case.
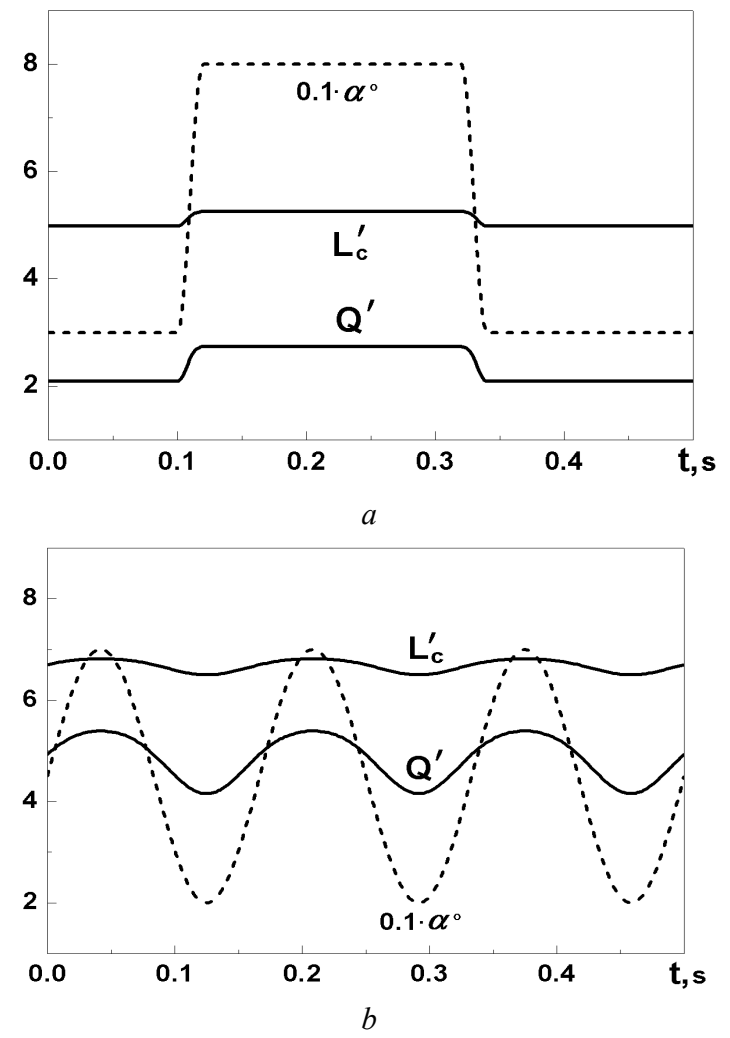

Fig. 12. Variation of $L_{c}$ and $Q$ under variation of $\alpha:(a)$ stepwise, $(b)$ periodic
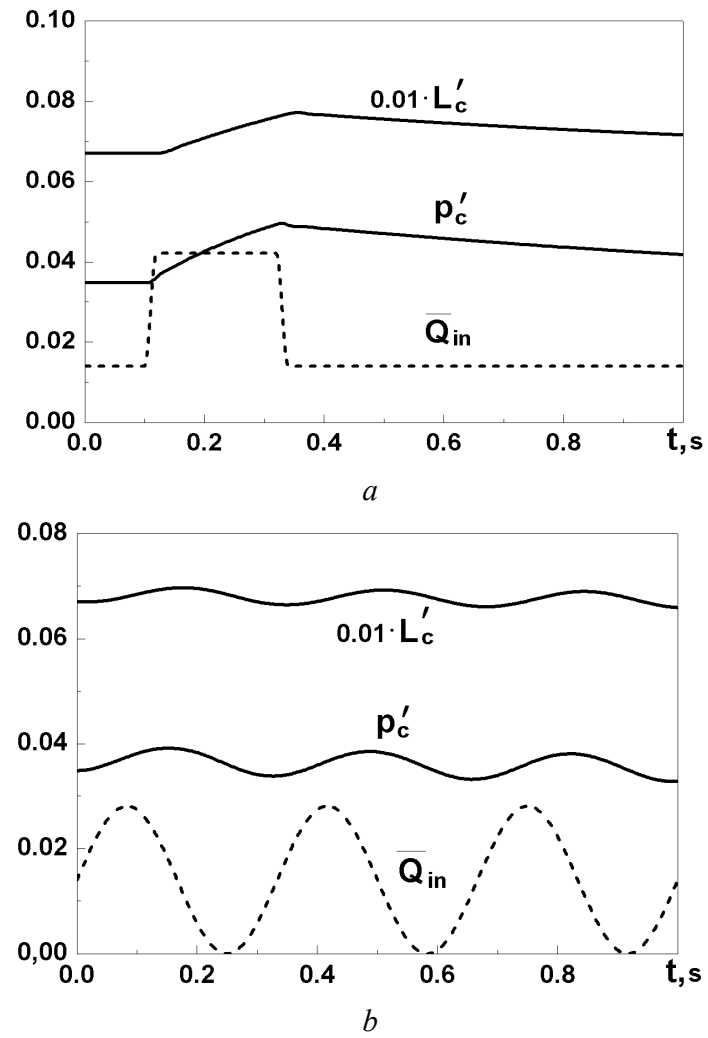

Fig. 13. Variation of $L_{c}$ and $p_{\mathrm{c}}$ under variation of $\dot{Q}_{\text {in }}:(a)$ stepwise, $(b)$ periodic 
As is known, the similarity parameter $\beta=\sigma_{v} / \sigma \geq 1$ is of important for unsteady ventilated cavities. The higher the value of the parameter $\beta$, the stronger the dynamic behavior of a ventilated cavity differs from the dynamic behavior of a natural supercavity with the same starting cavitation number $\sigma_{0}$. If the certain critical value $\beta_{c r}$ is exceeded, then the ventilated cavity stability loss may occur $[2,14,15]$. After that, the intense self-induced cavity oscillation (pulsation) is settled. In the calculations, we can obtain cavities with the same $\sigma$ but with different $\beta$ by varying the parameters $H$ and $V$.

In the case of a free closing axisymmetric gas-filled cavity, one determines the minimum value $\beta_{c r}=1+\pi^{2} / 6=2.645$ (see, for example, [14]). It was shown in our work [2], that if the cavity closes on a cylinder, then the value $\beta_{c r}$ depends on the cylinder diameter. Namely, with increasing the relative diameter $D_{b} / D_{c}$ the value of $\beta_{c r}$ increases, and the frequency $f$ of the arising self-induced oscillation decreases.

Fig. 14 shows the graphs of variation of $\bar{L}_{c}(a)$ and $p_{\mathrm{c}}{ }^{\prime}(b)$ at fixed excess gas supply $\bar{Q}_{\mathrm{ext}}=0.04$ for $V=40.0 \mathrm{~m} / \mathrm{s}, \quad \beta_{0}=1.319<\beta_{c r}(a)$ and $V=20.0 \mathrm{~m} / \mathrm{s}$, $\beta_{0}=5.275>\beta_{c r}(b)$ (compare with Fig. 7).
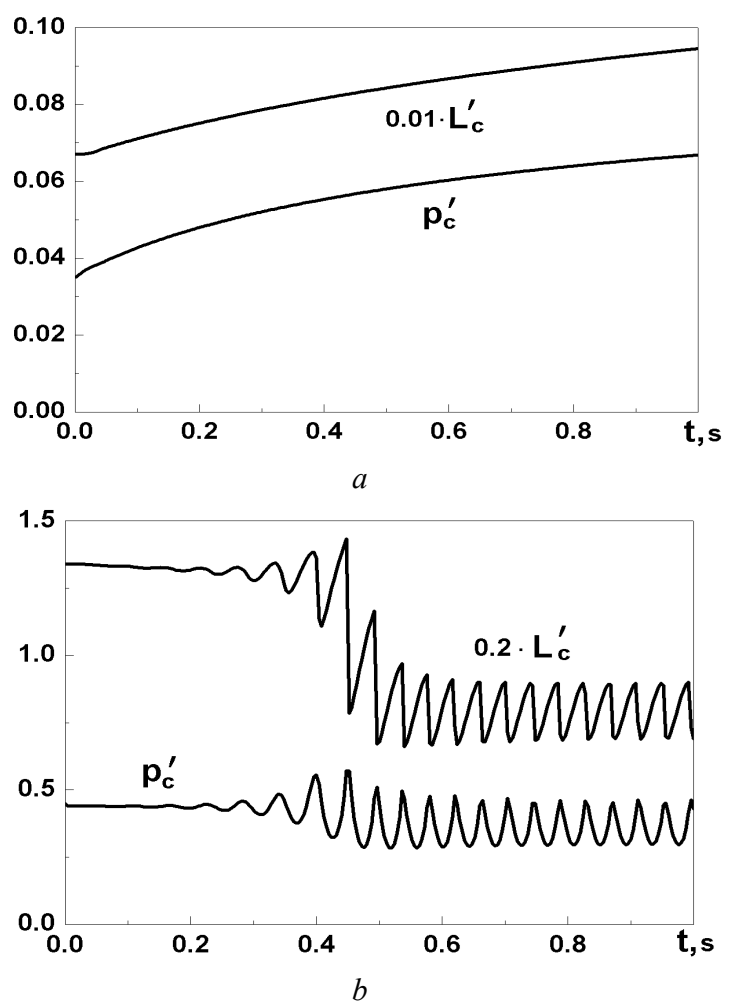

Fig. 14. Effect of parameter $\beta$ on variation of $L_{c}$ and $p_{c}$ for fixed $\dot{Q}_{i n}:(a) \quad \beta_{0}=1.319$; (b) $\beta_{0}=5.275$
As one can see in Fig. 14, $a$, the cavity is stable when $\beta_{0}<\beta_{c r}$. In Fig. 14, $b$, when $\beta_{0}>\beta_{c r}$, loss of stability occurs, and the self-induced discontinuous cavity oscillation with the fundamental frequency $f=23.8 \mathrm{~Hz}$ is settled. In practice, the cavity stability loss is always extremely undesirable.

When analyzing the self-induced oscillation of ventilated cavities, it is convenient to consider the set of nonlinear equations (32) - (34) as a dynamic system with three phase variables $L_{c}(t), p_{c}(t), Q(t)$. In this case, a limit loop in a phase space corresponds to the self-induced cavity oscillation. Fig. 15 shows the three-dimensional phaseplane portrait $(a)$ and the power spectral density $P$ of the cavity length oscillation $(b)$ for the cavity self-induced oscillation in Fig. 14, $b$. Here, $k=2 \pi f D_{b} / V$ is the reduced frequency.
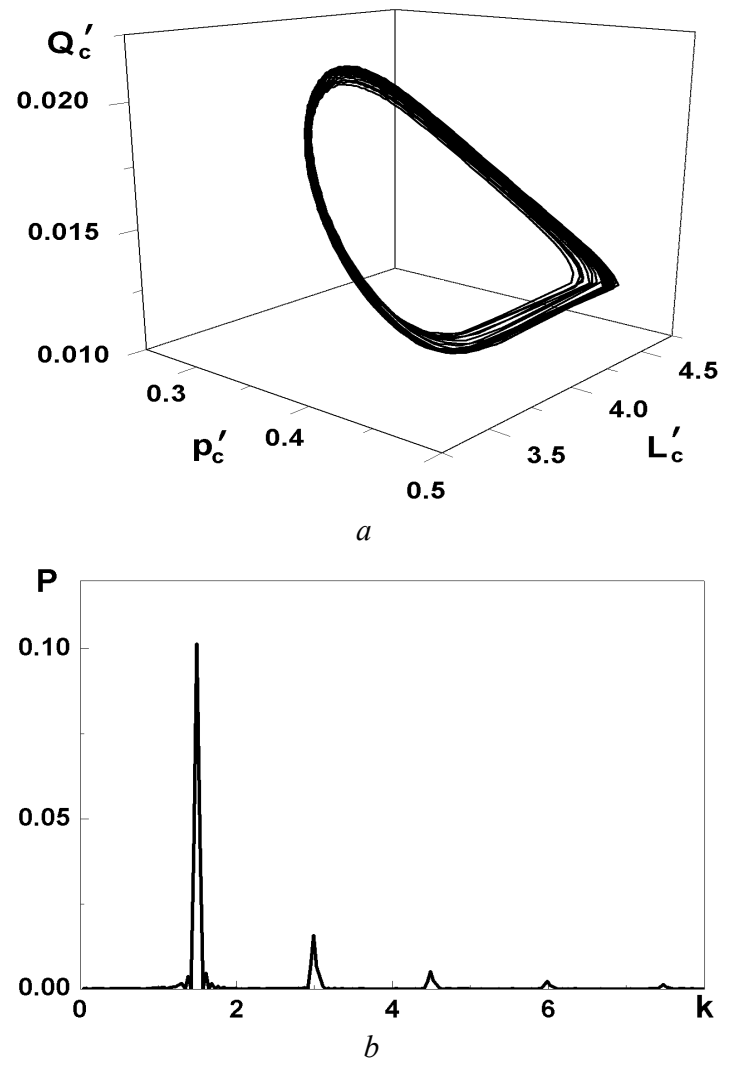

Fig. 15. Analysis of self-induced oscillation of ventilated partial cavity on a cylinder: $(a)$ phaseplane portrait; $(b)$ power spectral density of $L_{c}(t)$

\section{Comparison of unsteady behavior of plane and axisymmetric cavities}

A comparison of the results of computer simulation of unsteady plane and axisymmetric partial cavities shows 
that in both the cases the cavity reaction to external perturbation is delayed, which leads to the phase shift under the oscillatory perturbation.

The main difference is that the partial cavities on a cylinder ( $h<<D_{b}$, mathematical model of Section 4 ) react to external effects essentially weaker than the partial cavities on a plane. This is due to the fact that in this case the cavity dimensions are defined mainly by the parameter $D_{b}$ , which is fixed. Hence, both the considered methods of active control of the partial cavity on a cylinder are ineffective. On the contrary, these control methods are sufficiently effective for the partial cavity on a plane.

The second important difference is that for axisymmetric ventilated cavities, when $\beta>\beta_{c r}$, spontaneous or forced loss of stability and the occurrence of self-induced oscillation (pulsations) of cavities are possible. On the contrary, in the case of the plane ventilated cavities on a plane (mathematical model of Section 2), the stability loss does not appear for any $\beta$. One can say in this respect that the mathematical model of Section 4 better reflects reality, since the instability of the plane ventilated cavities is observed experimentally [15]. Also, it has been investigated theoretically [16].

\section{Conclusion}

The approximate methods for calculating the unsteady ventilated partial cavities created on the streamlined surfaces have been developed. The cases of both the cavity on a flat wall and the cavity past a ring flange on a cylinder surface are considered. In both the cases, rapid computational algorithms have been developed that make it possible to observe the behavior of unsteady cavities on a computer screen directly during calculation. A number of practical problems of active control of the partial cavities are considered. It was established that the control of the plane partial cavity by regulating the gas supply into the cavity is less effective than control by regulating the wedge-shaped cavitator angle. This is due to the relatively slow reaction of the cavity to the gas supply variation than to varying the cavitator shape. For the axisymmetric partial cavity past the flange on a cylinder, both the considered control methods appear ineffective when $h<<D_{b}$. In addition, control by regulating the gas supply into the cavity is difficult due to the possible loss of stability and the occurrence of selfinduced oscillation of the ventilated cavity.

\section{References}

[1] M. Perlin, and S. Ceccio, Mitigation of hydrodynamic resistance: methods to reduce hydrodynamic drag, World Scientfic Publishing Co. Pte. Ltd, 2015. https://dx.doi.org/10.1142/9789814612265

[2] V.N. Semenenko, "Instability of ventilated cavity that is closed on a body", J. of Applied Hydromechanics, vol. 13, no. 3, pp. 76-81, 2011.

[3] I.I. Yefremov, Teoriya kavitatsiynogo obtikannya [Linearized theory of cavitation flow],”, Kyiv, Ukraine: Naukova Dumka, 1974.

[4] V.N. Semenenko, "Calculation of Two-Dimensional Unsteady Supercavities at Arbitrary Time Dependence", International J. of Fluid Mechanics Research, vol. 31, no. 6, pp. 621-632, 2004. doi: 10.1615/InterJFluidMechRes.v31.i6.80

[5] G.V. Logvinovich, Gidrodinamika techeniy so svobodnymi granitsami [Hydrodynamics of Free- Boundary Flows], Kyiv, Ukraine: Naukova Dumka, 1969.

[6] G.V. Logvinovich and V.V. Serebryakov, "On Methods of Calculation of Slender Axisymmetric Cavity Shapes", J. of Hydromechanics, vol. 32, pp. 47-54, 1975.

[7] V.N. Semenenko, "Artificial cavitation. Physics and calculations", RTO-AVT/VKI Special Course on Supercavitating Flows, February 12-16, VKI, Brussels, Belgium, 2001.

[8] L. Barbaka, B.W. Pearce and P.A. Brandner, "Experimental investigation of ventilated cavity flow over a 3D wall mounted fence", in Proc. International Symposium on Transport Phenomena and Dynamics of Rotating Machinery, April 10-15, Honolulu, Hawaii, 2016.

[9] K.A. Lay et al., "Partial cavity drag reduction at high Reynolds Numbers", J. of Ship Research, vol. 54, no. 2, pp. 109-119, 2010.

[10] G.V. Logvinovich, et al., Techeniya so svobodnymi poverkhnostyami [Free-Surface Flows], Kyiv, Ukraine: Naukova Dumka, 1985.

[11] M.I. Gurevch, Teoriya struy idealnoy zhidkosti [The Theory of Jets in Ideal Fluids], 2nd ed., Moscow, Russia: Nauka, 1979.

[12] Y.D. Vlasenko and G.Y. Savchenko, "Study of the Parameters of a Ventilated Supercavity Closed on a Cylindrical Body", Supercavitation: Advances and Perspectives. Springer-Verlag, Berlin and Heidelberg, pp. 201-214. 2012. doi: 10.1007/978-3-642-23656-3

[13] J.H. Spurk, “On the gas loss from ventilated supercavities”, Acta Mechanica, vol. 155, pp. 125-135, 2002. https://doi.org/10.1007/BF01176238

[14] V.N. Semenenko, "Computer modeling of pulsations of ventilated supercavities", International J. of Fluid Mechanics Research, vol. 23 , nos. 3 \& 4, pp. 302-312, 1996. 
[15] J.-P. Franc, and J.-M. Michel, Fundamentals of Cavitation, Dordrecht, Boston, London: Kluwer Academic Publishers, 2004. doi: $10.1007 / 1-4020-2233-6$

[16] V.N. Semenenko, "Instability of a plane ventilated supercavity in an infinite stream", International J. of Fluid Mechanics Research, vol. 23, nos. 1 \& 2, pp. 134-143, 1996.

\title{
Расчет нестационарных вентилируемых пристенных каверн
}

\author{
Владимир Семененко, Елена Наумова
}

Аннотация. Разработаны приближенные методы расчета нестационарных вентилируемых пристенных каверн, создаваемых на плоских и цилиндрических обтекаемых поверхностях. Рассмотрены случаи плоских пристенных каверн за тонким клиновидным кавитатором и осесимметричных пристенных каверн, образованных за кольцевым выступом на поверхности бесконечного кругового ичилиндра. Приведены результаты компьютерного моделирования нестационарных вентилируемых пристенных каверн обоих типов. Дано сравнение нестационарного поведения плоских и осесимметричных вентилируемых пристенных каверн. Дан сравнительный анализ методов управления пристенными кавернами путем изменения формы кавитатора и путем регулирования расхода газа на поддув каверны. Показано, что для пристенной каверны на плоскости первый метод является более эффективным. Для осесимметричной пристенной каверны на цилиндре оба метода управления оказались малоэффективными.

Ключевые слова: пристенная каверна; вентилируемая каверна; нестационарная каверна; метод дискретных особенностей; компьютерное моделирование.

\section{Розрахунок нестаціонарних вентильованих пристінних каверн}

\section{Володимир Семененко, Олена Наумова}

Анотація. Розроблено наближені методи розрахунку нестаціонарних вентильованих пристінних каверн, щзо створюються на плоских і ичліндричних обтічних поверхнях. Розглянуто випадки плоских пристінних каверн за тонким клиноподібним кавітатором і осесиметричних пристінних каверн, утворених за кільцевим виступом на поверхні нескінченного кругового ииліндра. Наведено результати комп'ютерного моделювання нестачіонарних вентильованих пристінних каверн обох типів. Дано порівняння нестачіонарноъ поведінки плоских і осесиметричних вентильованих пристінних каверн. Дано порівняльний аналіз методів управління пристінними кавернами шляхом зміни форми кавітатора і шляхом регулювання витрати газу на піддув каверни. Показано, щчо для пристінної каверни на площині перший метод є більш ефективним. Для осесиметричної пристінної каверни на циліндрі обидва методи управління виявилися малоефективними.

Ключові слова: пристінна каверна; вентильована каверна; нестаціонарна каверн; метод дискретних особливостей; комп'ютерне моделювання. 